\title{
Determinants of survival in pulmonary Langerhans' cell granulomatosis (histiocytosis $\mathrm{X}$ )
}

\author{
A. Delobbe*, J. Durieu*, A. Duhamel**, B. Wallaert* and the Groupe d'Etude en \\ Pathologie Interstitielle de la Société de Pathologie Thoracique du Nord
}

Determinants of survival in pulmonary Langerhans' cell granulomatosis (histiocytosis $X$ ). A. Delobbe, J. Durieu, A. Duhamel, B. Wallaert and the Groupe d'Etude en Pathologie Interstitielle de la Société de Pathologie Thoracique du Nord. @ERS Journals Ltd 1996. ABSTRACT: The course of pulmonary Langerhans' cell granulomatosis (pulmonary LCG) is variable, difficult to predict and ranges from spontaneous remission to progressive respiratory insufficiency and death. To identify the determinants of survival, we performed a survival analysis on $\mathbf{4 5}$ patients with pulmonary LCG.

The patients were aged $28 \pm 10$ yrs (mean \pm SD) (range 12-62 yrs), 32 males and 13 females, almost exclusively current smokers $(96 \%)$, and $78 \%$ presented symptoms at the time of diagnosis. Diagnosis was made by lung biopsy in 25 patients $(56 \%)$ and by bronchoalveolar lavage (BAL) analysis in 20 patients $(44 \%)$. The patients were followed for a median period of 6 yrs (range 1-29 yrs ) after the diagnosis.

During the period of observation, $33(73 \%)$ patients survived (median follow-up period = 5.8 yrs; range, 1-29 yrs) and $12(27 \%)$ died or underwent lung transplantation (median follow-up period $=8.4 \mathrm{yrs}$; range $1.4-16.1 \mathrm{yrs}$ ). The median survival was approximately 13 years. A univariate analysis demonstrated that diminished survival was significantly associated with: an older age at diagnosis $(p=0.0001)$; a lower forced expiratory volume in one second/forced vital capacity (FEV1/FVC) ratio at diagnosis $(p=0.005)$; a higher residual volume/total lung volume $(\mathrm{RV} / \mathrm{TLC})$ ratio at diagnosis $(p=0.02)$; and steroid therapy during follow-up ( $p=0.03$ ). Additional predictive information on mortality was: age $>26$ yrs (sensitivity $83 \%$, specificity 64\%); FEV1/FVC ratio <0.66 (sensitivity $75 \%$, specificity $86 \%$ ); and a $\mathrm{RV} / \mathrm{TLC}$ ratio $>0.33$ (sensitivity $75 \%$, specificity $63 \%$ ). In multivariate Cox analysis, the combination of factors which gave the best prognostic value was FEV1/FVC ratio and age $(\mathbf{p}<0.01)$.

The present findings suggest that adverse prognosis factors at diagnosis in pulmonary Langerhans' cell granulomatosis include older age, lower FEV1/FVC ratio and higher RV/TLC ratio, with additional predictive information on mortality if aged $>26$ yrs, FEV1/FVC ratio $<0.66$, and $\mathrm{RV} / \mathrm{TLC}$ ratio $>0.33$.

Eur Respir J., 1996, 9, 2002-2006.
*Service de Pneumologie et Immuno-allergologie, Hôpital A. Calmette, and INSERM U416 Institut Pasteur, Lille Cedex, France. **Centre d'Etudes et de Recherche en Informatique Médicale, Faculté de Médecine, Lille, France.

Correspondence: B. Wallaert Clinique des Maladies Respiratoires Hôpital Calmette

Bld du Professeur Jules Leclerc 59037 Lille Cedex

France

Keywords: Histiocytosis X interstitial lung disease

Langerhans' cell granulomatosis lung

survival

Received: December 181995 Accepted after revision June 161996
Pulmonary Langerhans' cell granulomatosis (pulmonary LCG), also referred to as histiocytosis $\mathrm{X}$, is a rare granulomatous disease of unknown aetiology, that represents less than $4 \%$ of all forms of interstitial lung disease [1]. The disease occurs almost exclusively in smokers. The course of the disease is variable, difficult to predict, and may range from spontaneous remission to progressive respiratory insufficiency and death [2-7]. In a minority of patients, progressive disease leads to respiratory insufficiency over a period of months to years.

The percentage of deaths can range from $2 \%$ [8] to $30 \%$ [2-9]. Most authors consider that adverse prognostic factors in pulmonary LCG include: advanced age at diagnosis; prolonged constitutional symptoms; numerous cysts on computed tomography; decreased lung transfer factor for carbon monoxide $(T \mathrm{~L}, \mathrm{CO})$ at diagnosis, recurrent pneumothorax; multisystem generalized disease; and continuation of tobacco consumption [2, 3, 6, 9-13]. Some authors have observed a beneficial response to corticosteroid therapy [2] or chemotherapeutic agents [3]. However, the efficacy of treatment currently used in pulmonary LCG has so far not been demonstrated.

Few investigations have identified the clinical features of pulmonary LCG that are independently associated with a diminished survival. The purpose of this study was to identify the causes of death and the determinants of survival at the time of diagnosis in pulmonary LCG.

\section{Patients and methods}

\section{Patients}

Forty five patients with pulmonary LCG were included in this study. The time of disease onset was defined as the patient's recollection of first appearance of chest symptoms (dyspnoea or pneumothorax) or the first documented chest roentgenogram demonstrating interstitial 
Table 1. - Clinical characteristics of the study subjects with pulmonary Langerhans' cell granulomatosis (LCG) at the time of diagnosis

\begin{tabular}{lc}
\hline Age yrs & $28 \pm 10$ \\
Male gender \% & 71 \\
Smoking history \% & \\
Nonsmoker & 4 \\
$\quad$ Current smoker & 96 \\
Symptoms \% & \\
$\quad$ None & 22 \\
Dyspnoea & 44 \\
Spontaneous pneumothorax & 16 \\
Systemic complaints & 11 \\
(weight loss, fever, fatigue) & \\
Lymph nodes & 5 \\
Diabetes insipidus & 2 \\
\hline
\end{tabular}

Results are expressed as mean \pm SD for continuous variables and as a percentage of all study subjects for categorical variables.

lung disease. Patients were classified as current smokers ( $\geq 2$ pack-years of cigarettes and a smoker at the time of initial evaluation) or as nonsmokers. The demographic features of the study population are shown in table 1 , and are similar to the demographic characteristics of other reported series [2,3] with a large percentage of male cigarette smokers. At the time of the diagnosis, 35 patients $(78 \%)$ presented with symptoms; 27 patients $(60 \%)$ had pulmonary symptoms and eight patients (18\%) had extrapulmonary symptoms without obvious pulmonary symptoms. Patients whose follow-up was less than $1 \mathrm{yr}$ were excluded from the study.

The diagnosis of pulmonary LCG was confirmed by lung biopsy in 25 patients (open lung biopsy 24 cases; transbronchial lung biopsy one case), or by bronchoalveolar lavage (BAL) analysis in 20 subjects. The lung biopsy demonstrated destructive granulomatous lesions containing Langerhans' cells [14]. When applicable, immunohistochemical staining of Langerhans' cells was positive with antibodies to S-100 protein, as reported by WEBBER et al. [15], and electron microscopy analysis revealed Birbeck granules ( $\mathrm{X}$ body) within Langerhans' cells. BAL cell analysis was performed with immunocytochemical staining to CD1a antigen expressed on the surface of Langerhans' cells using the anti-T6 monoclonal antibody (Ortho Diagnostic systems, NJ, USA) [16]. The diagnosis was considered when more than $5 \%$ of BAL cells stained with OKT6 antibodies [17]. Electron microscopy study of BAL cells was performed in two cases and revealed intracytoplasmic Birbeck granules in Langerhans' cells [18].

\section{Pulmonary function tests}

The pulmonary function tests consisted of standard spirometry using a Medical Graphics 1070 system (St Paul, MN, USA), and lung volumes via body plethysmography using a Medical Graphics 1085 system. Singlebreath $T_{\mathrm{L}, \mathrm{CO}}$ was measured using the Medical Graphics 1070 system. Results were also expressed as percentage of predicted values [19]. Pulmonary function parameters at the time of diagnosis are presented in table 2 and showed a tendency to low values of forced expiratory volume in one second (FEV1), forced vital capacity (FVC),
Table 2. - Functional characteristics of the study subjects with pulmonary LCG at the time of diagnosis

\begin{tabular}{lrl}
\hline FEV 1 \% pred & 70 & $(32-118)$ \\
FVC \% pred & 77 & $(39-111)$ \\
FEV $1 /$ FVC \% & 75 & $(43-106)$ \\
TLC \% pred & 87 & $(50-130)$ \\
RV \% pred & 101 & $(59-219)$ \\
RV/TLC \% & 33 & $(19-56)$ \\
TL,CO/VA \% pred & 82 & $(23-142)$ \\
\hline
\end{tabular}

Results are expressed as median, and range in parenthesis. LCG: Langerhans' cell granulomatosis; FEV1: forced expiratory volume in one second; FVC: forced vital capacity; TLC: total lung capacity; RV: residual volume; $T \mathrm{~L}, \mathrm{CO}$ : transfer factor of the lung for carbon monoxide; $V \mathrm{~A}$ : alveolar volume; $\%$ pred: percentage of predicted value.

total lung capacity (TLC) and $T_{\mathrm{L}}, \mathrm{CO} /$ alveolar volume $\left(V_{\mathrm{A}}\right)$ associated with high values of residual volume (RV) and $\mathrm{RV} / \mathrm{TLC}$ ratio. At the time of diagnosis, $35 \%$ of the study subjects had normal pulmonary function; $33 \%$ had an obstructive pattern; $27 \%$ had a restrictive pattern and $5 \%$ had a mixed pattern. In the group of patients who developed a terminal respiratory failure, $88 \%$ had an obstructive pattern.

\section{Chest radiographs}

Chest radiographs were performed in the posteroanterior projection and were independently interpreted by two radiologists, who were unaware of the clinical data. Agreement between the two readers was obtained by reaching a consensus to identify chest radiographic abnormalities according to the International Labour Organization (ILO) classification of radiographs of pneumoconioses [20]; the interobserver correlation coefficient was 0.89 .

\section{Statistical analysis}

The following parameters were analysed for their prognostic value on survival: age, sex, pulmonary symptoms, cessation of tobacco consumption, ILO profusion category, treatment with corticosteroids, and the functional variables. All analyses were performed with Statistical Analysis System (SAS) software (SAS Institute Inc., Cary, NC, USA). The association between the continuous variables were tested using Spearman's correlation coefficient. For discrete parameters, survival curves were calculated based on the method of KAPLAN and MEIER [21]. A log rank test [22] was used to determine whether significant differences existed between curves. Risk ratio were calculated using the MANTEL [23] estimator. The prognostic value of continuous variables (age and functional parameters) was studied using the Cox $[24,25]$ proportional hazards model. The graphical method using survival curve estimates based on the residuals was performed to check the validity of the proportional hazard assumption [25]. The parameters significant at the 0.15 level for survival were introduced in a Cox proportional hazards regression analysis of survival, with both forward and best subset selection [26, 27]. Receiver operating characteristic (ROC) analysis was performed to determine cut-off values associated with the mortality for the continuous parameters. 


\section{Results}

Of 45 patients with pulmonary LCG, the median period of observation from onset of respiratory symptoms was 6 yrs (range 1-29 yrs). During this period of observation, 33 subjects $(73 \%)$ survived (Group A) and 12 $(27 \%)$ died or underwent lung transplantation (Group B). The median follow-up period from onset of respiratory symptoms was 5.8 yrs (range 1-29 yrs) in Group A, and 8.4 yrs (range 1.4-16.1 yrs) in Group B.

Nine out of the 12 subjects (Group B) developed a terminal respiratory failure (six died quickly within $2.5 \mathrm{yrs}$ after the diagnosis and three required a lung transplantation). Two patients died due to a nonresectable pulmonary neoplasm (epidermoid carcinoma stage IV diagnosed concurrently with pulmonary LCG, and adeno-carcinoma stage IIIB diagnosed 16 yrs after the diagnosis of pulmonary LCG). The last patient died following a cardiac arrest 12 yrs after the diagnosis of pulmonary LCG. According to these data, it was demonstrated that the subjects with pulmonary LCG had a median survival of approximately 13 yrs from the date of the diagnosis (fig. 1).

Eighteen patients (39\%) quit smoking during the follow-up period, a median of 2.8 yrs (range 0-26 yrs) after the time of diagnosis.

Four patients exhibited extrapulmonary involvement with LCG during the follow-up period: two had lymph node involvement at diagnosis, one of whom developed bone lesions during the follow-up period; bone lesions appeared in one other during the follow-up period; and one presented a diabetes insipidus at the time of diagnosis with a favourable evolution. These four patients survived but the small number did not allow statistical analysis.

Twenty three patients (52\%) were treated with immunosuppressive drugs: 20 of these 23 patients were treated with corticosteroids (table 3 ). Nineteen patients were treated because of severe abnormalities of pulmonary function and four because of systemic complaints. Corticosteroid treatment was given for a median period of $1.1 \mathrm{yrs}$ (range 0.2-8.4 yrs), and was introduced after a median period of 0.1 yrs (range 0-6.9 yrs) from the date of diagnosis.

The effects of the clinical, radiological and functional variables on survival are presented in table 4. A

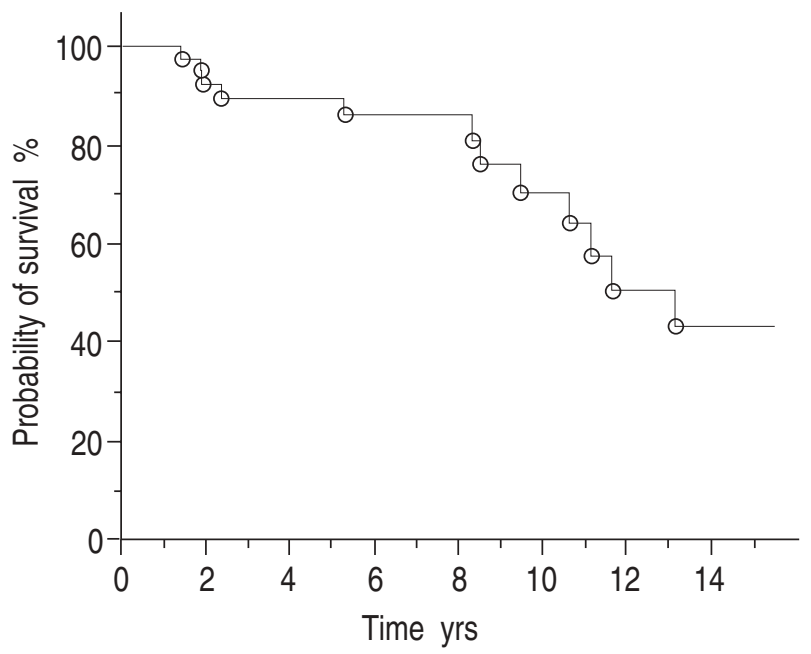

Fig. 1. - Actuarial curve for survival from onset of respiratory symptoms for all patients with pulmonary Langerhans' cell granulomatosis (LCG) $(\mathrm{n}=45)$. The Kaplan-Meier method was used to estimate the survival distribution.
Table 3. - Treatment regimen for the study of subjects with pulmonary Langerhans' cell granulomatosis (LCG)

\begin{tabular}{lrr}
\hline Treatment regimen & \multicolumn{2}{c}{ Subjects } \\
& $\mathrm{n}$ & $\%$ \\
\hline None & 22 & 48 \\
Corticosteroids alone & 18 & 40 \\
Corticosteroids and cyclophosphamids $^{\S}$ & 2 & 5 \\
Polychemotherapy $^{\#}$ & 1 & 2 \\
Chlorambucil* $_{\text {Vinblastine and azathioprin }}$ & 1 & 2 \\
\hline
\end{tabular}

§: cyclophosphamide used for 4 and 3 months before death, repectively; \#: polychemotherapy for $1.5 \mathrm{yrs}$ consisted of 8 courses of etoposide and 1 course of ifosfamide, mitoguazon, vinorelbin and etoposide; *: chlorambucil used for $2.2 \mathrm{yrs}$; vinblastin used for $0.9 \mathrm{yrs}$ and azathioprine for $0.8 \mathrm{yrs}$.

univariate analysis demonstrated that diminished survival was significantly associated with an older age at diagnosis (hazard ratio $(\mathrm{HR})=1.12 ; 95 \%$ confidence interval $(95 \%$ $\mathrm{CI})=1.06-1.18$; $\mathrm{p}=0.0001$ ); a lower $\mathrm{FEV} 1 / \mathrm{FVC}$ ratio at diagnosis $(\mathrm{HR}=0.94 ; 95 \% \mathrm{CI}=0.90-0.98 ; \mathrm{p}=0.005)$; a higher RV/TLC ratio at diagnosis ( $\mathrm{HR}=1.09$; $95 \% \mathrm{CI}=1.01-1.18$; $\mathrm{p}=0.02)$ and corticosteroid therapy during follow-up $(\mathrm{HR}=$ $2.42 ; 95 \% \mathrm{CI}=0.52-11.25 ; \mathrm{p}=0.03)$. For these adverse prognostic factors, additional predictive information on mortality was provided if age was $>26$ yrs (sensitivity $83 \%$, specificity $64 \%$ ); FEV1/FVC ratio $<0.66$ (sensitivity $75 \%$, specificity $86 \%$ ) and RV/TLC ratio was $>0.33$ (sensitivity $75 \%$, specificity $63 \%$ ). In multivariate Cox analysis, the combination of factors which gave the best prognostic value was $\mathrm{FEV} 1 / \mathrm{FVC}$ ratio and age $(\mathrm{p}<0.01)$. A significant correlation was found between FEV1/FVC ratio and $\mathrm{RV} / \mathrm{TLC}$ ratio $(\mathrm{p}<0.001)$. In addition, no linear relationship was found between the age and FEV1/FVC ratio $(\mathrm{p}=0.2)$, and between the age and $\mathrm{RV} / \mathrm{TLC}$ ratio $(p=0.09)$. Sex ratio, presence of pulmonary symptoms at the time of diagnosis, ILO profusion category on chest radiographic film findings, $T \mathrm{~L}, \mathrm{CO}$ at the time of diagnosis, and continuation of tobacco consumption were not associated with diminished survival. The present findings showed similar adverse prognostic factors for the

Table 4. - Effect of clinical and functional variables at the time of diagnosis and of steroid therapy during follow-up on survival of the 45 patients with pulmonary LCG

\begin{tabular}{llcl}
\hline & HR & $95 \%$ CI & p-value \\
\hline Age & 1.12 & $1.06-1.18$ & 0.0001 \\
$\begin{array}{l}\text { Male gender } \\
\text { Pulmonary symptoms }\end{array}$ & 1.23 & $0.24-6.19$ & 0.8 \\
$\quad \begin{array}{l}\quad s \text { none } \\
\text { Cessation of tobacco }\end{array}$ & 3.40 & $0.90-12.80$ & 0.07 \\
$\quad$ consumption $v s$ none & 3.03 & $0.87-10.55$ & 0.08 \\
Treatment with & & & \\
$\quad$ corticosteroids $v s$ none & 2.42 & $0.52-11.25$ & 0.03 \\
ILO profusion category & 1.8 & $0.83-4.04$ & 0.13 \\
FEV1 & 0.97 & $0.94-1.00$ & 0.08 \\
FVC & 1.01 & $0.97-1.05$ & 0.8 \\
FEV1/FVC ratio & 0.94 & $0.90-0.98$ & 0.005 \\
TLC & 1.05 & $0.99-1.10$ & 0.07 \\
RV & 1.01 & $0.99-1.03$ & 0.1 \\
RV/TLC ratio & 1.09 & $1.01-1.18$ & 0.02 \\
TL,CO/VA & 0.99 & $0.97-1.01$ & 0.4 \\
\hline
\end{tabular}

HR: hazard ratio; 95\% CI: 95\% confidence interval; ILO: International Labour Organization. For further definitions see legend to table 2 . 
Table 5. - Effect of clinical and functional variables at the time of diagnosis and of steroid therapy during followup on evolution to terminal respiratory failure of the 45 patients with pulmonary LCG

\begin{tabular}{|c|c|c|c|}
\hline & HR & $95 \% \mathrm{CI}$ & p-value \\
\hline Age & 1.12 & $1.05-1.19$ & 0.0005 \\
\hline Male gender & 1.57 & $0.3-8.25$ & 0.6 \\
\hline $\begin{array}{l}\text { Pulmonary symptoms } \\
\text { vs none }\end{array}$ & 3.69 & $0.76-17.96$ & 0.11 \\
\hline $\begin{array}{l}\text { Cessation of tobacco } \\
\text { consumption } v s \text { none } \\
\text { Treatment with }\end{array}$ & 10.57 & $1.29-86.34$ & 0.03 \\
\hline corticosteroids $v s$ none & 2.44 & $0.50-11.28$ & 0.03 \\
\hline ILO profusion category & 1.7 & $0.80-4.12$ & 0.16 \\
\hline FEV1 & 0.99 & $0.94-1.00$ & 0.07 \\
\hline $\mathrm{FVC}$ & 0.98 & $0.94-1.03$ & 0.5 \\
\hline FEV1/FVC ratio & 0.95 & $0.90-0.99$ & 0.03 \\
\hline TLC & 1.02 & $0.97-1.08$ & 0.4 \\
\hline RV & 1.01 & $0.99-1.03$ & 0.2 \\
\hline $\mathrm{RV} / \mathrm{TLC}$ ratio & 1.11 & $1.02-1.21$ & 0.01 \\
\hline$T \mathrm{~L}, \mathrm{CO} / V_{\mathrm{A}}$ & 0.98 & $0.95-1.00$ & 0.07 \\
\hline$T \mathrm{~L}, \mathrm{CO} / V_{\mathrm{A}}<55 \%$ & 0.21 & $0.05-0.89$ & 0.03 \\
\hline
\end{tabular}

For definitions see legend to tables 2 and 4.

nine subjects who developed a terminal respiratory failure (table 5). For these nine subjects, $T \mathrm{~L}, \mathrm{CO} / V_{\mathrm{A}}<55 \%$ of the predicted value at the time of diagnosis was significantly associated $(\mathrm{HR}=0.21 ; 95 \% \mathrm{CI}=0.05-0.89 ; \mathrm{p}=0.03)$ with evolution to terminal respiratory failure.

\section{Discussion}

The present results indicate that patients with pulmonary LCG have a median survival of approximately 13 yrs from the date of diagnosis and that adverse prognostic factors include an older age, a lower $\mathrm{FEV} 1 / \mathrm{FVC}$ ratio, a higher RV/TLC ratio, and steroid therapy during followup. Additional predictive information on mortality was demonstrated when age was $>26$ yrs, FEV1/FVC ratio $<0.66$, and $\mathrm{RV} / \mathrm{TLC}$ ratio $>0.33$ at the time of diagnosis.

The percentage of dead subjects $(27 \%)$ was similar to that reported by BASSET et al. [2] and SADOUN et al. [9]. FRIEDMAN et al. [8] reported a lower percentage (2\%) but a significant number of patients had persistent abnormalities or experienced subsequent progression. Death was mainly due to terminal respiratory failure, and secondly to the development of a pulmonary neoplasm [13]. In the present series, lung neoplasm occurred concurrently in one patient and 16 yrs later in the second. The percentage of pulmonary malignancies associated with pulmonary LCG is similar to that of EGELER et al., who found 3.5\% of pulmonary cancer during the course of pulmonary LCG [4]. Clearly, tobacco consumption is the most important factor for the development of pulmonary neoplasm.

Disseminated LCG with or without pulmonary involvement is thought to have a worse prognosis than pulmonary LCG involving the lung alone [3]. Interestingly, the four subjects with extrapulmonary organs invaded by LCG without severe dysfunction were alive at the end of the follow-up period. However, the small number of these subjects did not permit statistical conclusions to be made and these data should be confirmed in larger studies.

Typically, radiographic abnormalities are bilateral, symmetrical, diffuse and predominate in the upper and middle lobes, with sparing of the costrophrenic angles [2]. Nodular lesions, as evaluated by ILO classification, are present in the early stages, whereas cysts and bullae predominate in more advanced disease. Because radiographs are insensitive in detecting small cystic lesions, patients with low ILO profusion might demonstrate severe airway obstruction on pulmonary function tests. BASSET and co-workers [28] reported that the degree of dissemination of nodular lesions within the lungs, presence or absence of cysts, diameter of nodular opacities or diameter of lesion had no prognostic value. High-resolution computed tomography (HRCT) has proved to be of considerable value in the diagnosis of pulmonary LCG, and allows a precise identification both of nodular and cystic lesions $[29,30]$. However, we were unable to identify the HRCT determinants of survival because only 12 subjects underwent HRCT at the time of diagnosis.

Pulmonary function tests are highly variable during the course of pulmonary LCG. Evidence of airway obstruction is common and usually characteristic of the disease. Decreased FEV1/FVC ratio and increased RV/TLC ratio are a common finding, especially in patients with extensive cystic lesions $[31,32]$. The specific factors that were found to be independently associated with survival represent a small portion of markers of disease severity. As previously emphasized in idiopathic pulmonary fibrosis [33], measures of lung function are highly interdependent and the present study only demonstrates that, once the effect of FEV1/FVC ratio is taken into account, the effect of the other measures of lung function in predicting survival is negligible. The fact that severe airway obstruction is associated with a decreased survival may be due to the fact that the diagnosis was made at the end-stage of the disease. Indeed, in the early stage, the granulomas have a strong tendency to occur around bronchioles and are associated with mild restrictive changes and/or reduction in $T \mathrm{~L}, \mathrm{CO}$. At the end-stage, cystic lesions of variable size are present and pulmonary function testing commonly demonstrates evidence of airflow obstruction, air-trapping and reduced transfer factor.

In the present study, absence of immunosuppressive therapy, mainly steroids, and the continuation of tobacco consumption were not associated with diminished survival. Because of the high rate of spontaneous remission, and the rarity of the disease, there are no reliable data concerning the efficiency of various treatment schedules on survival. Several studies have reported the effects of corticosteroids combined or not with chemotherapeutic agents or combination chemotherapy often used in generalized disease [12, 34]. However, none of these studies have reported the effectiveness of such treatments on survival and on the long-term course of the disease. In the present study, Group B patients (deceased or lung transplanted) had received significantly more treatment and significantly more of them had completely ceased their tobacco consumption compared to Group A patients (survivors). It is likely that subjects who were treated or have completely stopped their tobacco consumption had more advanced pulmonary LCG. Importantly, this study was not established as a treatment trial, and the absence of relationship between survival and treatment or cessation of tobacco consumption should be interpreted cautiously. Clearly, patients with pulmonary LCG should stop smoking. However, although a beneficial effect of smoking cessation on pulmonary LCG has been reported [35], such an effect has never been formally established. 
Our results suggest that severe deterioration of pulmonary function at the time of the diagnosis, especially obstructive ventilatory defect, affects survival of patients with pulmonary Langerhans' cell granulomatosis. These findings raise the intriguing question of the validity of the beneficial effects of an early treatment in severe pulmonary Langerhans' cell granulomatosis. Future studies and prospective multicentre trials should assess whether identification of clinical, functional and radiological factors, including high resolution computed tomography, at the time of diagnosis and during the first year of follow-up may provide useful information in the management and treatment of pulmonary Langerhans' cell granulomatosis.

Members of the GEPI: F. Bart (Bethune, F); A. Benard (Roubaix, F); J.F. Bervar (Arras, F); E. Cardot (Bethune, F); E. Dansin (Lille, F); C. Degive (Seraing, B); L. Delaunois (Mont-Godinne, B); E. Delepoulle (Lens, F); A. Delobbe (Lille, F); A. Duhamel (Lille, F); A. Duthoit (Roubaix, F); G. Demarcq (Valenciennes, F); Ch. Deroubaix (Dunkerque, F); C. Florin (Douai, F); X. Ficheroulle (Tourcoing, F); F. Fortin (Lille, F); B. Fourquet (Calais, F); J.M. Grosbois (Lille, F); M. Gustin (Liege, B); F. Herengt (Arras, F); J.J. Lafitte (Lille, F); Y. Lierman (Arras, F); C.H. Marquette (Lille, F); E. Maetz (Douai, F); B. Mellin (Dunkerque, F); F. Pagnier (Somain, F); T. Perez (Lille, F); M. Radermecker (Liege, B); Ph. Ramon (Lille, F); D.O. Rodenstein (Bruxelles, B); J.P. Roux (Valenciennes, F); B. Stach (Valenciennes, F); F. Steenhouwer (Roubaix, F); J. Soots (Bethune, F); V. Tack (Calais, F); I. Tillie-Leblond (Lille, F); A.B. Tonnel (Lille, F); F. Varlet (Bethune, F); B. Wallaert (Lille, F); C. Wallaert (Lens, F).

\section{References}

1. Gaensler EA, Carrington CB. Open biopsy for chronic diffuse infiltrative lung disease clinical, roentgenographic, and physiologic correlations in 502 patients. Ann Thorac Surg 1980; 30: 411-426.

2. Basset F, Corrin B, Spencer H, et al. Pulmonary histiocytosis X. Am Rev Respir Dis 1978; 118: 811-820.

3. Marcy TW, Reynolds HY. Pulmonary histiocytosis X. Lung 1985; 163: 129-150.

4. Egeler RM, Neglia JP, Puccetti DM, Brennan CA, Nesbit ME. Association of Langerhans' cell histiocytosis with malignant neoplasms. Cancer 1993; 71: 865-873.

5. Hance AJ, Cadranel J, Soler P, Basser F. Pulmonary and extrapulmonary Langerhans' cell granulomatosis (histiocytosis X). Semin Respir Med 1988; 9: 349-368.

6. Nezelof C, Frileux H, Cronier-Sachot J. Disseminated histiocytosis $\mathrm{X}$ : analysis of prognostic factors based on a retrospective study of 50 cases. Cancer 1979; 44: 1824-1838.

7. Power MA, Askin FB, Creson DH. Pulmonary eosinophilic granuloma: 25 year follow-up. Am Rev Respir Dis 1984; 129: 503-507.

8. Friedman PJ, Liebow AA, Sokoloff J. Eosinophilic granuloma of lung. Medicine 1981; 60: 385.

9. Sadoun D, Valeyre D, Clerici C, Loiseau P, Battesti JP, Georges R. Clinical follow-up study in 33 patients with Langerhans' cell granulomatosis. Am Rev Respir Dis 1990; 141: A319.

10. Askin FB. Pulmonary eosinophilic granuloma. Am Rev Respir Dis 1984; 29: 503-507.

11. Lewis JG. Eosinophilic granuloma and its variants with special reference to lung involvement: a report of 12 patients. QJ Med 1964; 131: 337.

12. Schönfeld N, Frank W, Wenig S, et al. Clinical and radiologic features, lung function and therapeutic results in pulmonary histiocytosis X. Respiration 1993; 60: 38-44.

13. William G, Hocking MD, Swanson M. Multifocal eosinophilic granuloma. Cancer 1986; 58: 840-842.
14. Soler P, Kambouchner M, Valeyre D, Habce AJ. Pulmonary Langerhans' cell granulomatosis (histiocytocis X). Annu Rev Med 1992; 43: 105-115.

15. Webber D, Tron V, Askin F, Churg A. S-100 staining in the diagnosis of eosinphilic granuloma of lung. Am J Clin Pathol 1985; 84: 447-453.

16. Chollet S, Soler P, Dournovo P, Richard MS, Ferrans VJ, Basset F. Diagnosis of pulmonary histiocytosis X by immunodetection of Langerhans' cells in bronchoalveolar lavage fluid. Am J Pathol 1984; 115: 225-232.

17. Auerswald U, Barth J, Magnussen H. Value of CD1-positive cells in bronchoalveolar lavage fluid for the diagnosis of pulmonary histiocytosis X. Lung 1991; 169: 305-309.

18. Basset F, Soler P, Jaurand MC, Bignon J. Ultrastructural examination of bronchoalveolar lavage for diagnosis of pulmonary histiocytosis X. Thorax 1977; 32: 303-306.

19. Quanjer $\mathrm{Ph}$. Standardized lung function testing. Report working party, standardization of lung function tests. Bull Eur Physiopathol Respir 1983; 19 (Suppl. 5): 1-95.

20. International Labour Organisation. International classification of radiographs of pneumoconiosis: guidelines for the use of International Labour Organisation (ILO). Geneva, International Labour Office, 1980.

21. Kaplan EL, Meier P. Nonparametic estimation from incomplete observation. J Am Stat Assoc 1958; 53: 457481.

22. Peto R, Peto J. Asymptotically efficient rank invariant test procedures (with discussion). JR Stat Soc A 1972; 135: 185-206.

23. Mantel N. Evaluation of survival data and two new rank order statistics arising in its consideration. Cancer Chemother Rep 1966; 50: 163-170.

24. Cox DR. Regression models and life tables. JR Stat Soc Br 1972; 34: 187-220.

25. Cox DR, Oakes D. Analysis of survival data. London, Chapman and Hall, 1984.

26. Kalbfleisch JO, Prentice RL. The statistical analysis of failure time data. New York, J. Wiley, 1980.

27. Furnival GM, Wilson RW. Regressions by leaps and bounds. Technometrics 1974; 16: 499-511.

28. Lacronique J, Roth C, Battesti JP, Basset F, Chretien J. Chest radiological features of pulmonary histiocytosis $\mathrm{X}$ : a report based on 50 adult cases. Thorax 1982; 37: 104-119.

29. Brauner MW, Grenier P, Montasser MM, Mompoint D, Lenoir S. Pulmonary histiocytosis X: evaluation with high resolution CT. Radiology 1989; 172: 255-258.

30. Kulwiec E, Lynch DA, Aguayo SM, Schwarz MI, King TE Jr. Imaging of pulmonary histiocytosis X. Radiographics 1992; 12: 515-526.

31. Firedman PJ, Liebow AA, Sokoloff J. Eosinophilic granuloma of lung: clinical aspects of primary histiocytosis in the adult. Medicine (Baltimore) 1981; 60: 385-396.

32. Travis WD, Borok Z, Roum JH, Fenerstein I, Ferrans VJ, Crystal RG. Pulmonary Langerhans' cell granulomatosis (histiocytosis $\mathrm{X}$ ): a clinicopathologic study in 48 cases. Am J Surg Pathol 1993; 17: 971-986.

33. Schwartz DA, Helmers RA, Galvin JR, et al. Determinants of survival in idiopathic pulmonary fibrosis. Am J Respir Crit Care Med 1994; 149: 450-454.

34. Ladisch S, Gadner H. Treatment of Langerhans' cell histiocytosis: evolution and current approaches. Br J Cancer 1994; 70 (Suppl. XXIII): S41-S46.

35. Von Essen S, West W, Sitorius M, Rennard SI. Complete resolution of roentgenographic changes in a patient with pulmonary histiocytosis X. Chest 1990; 98: 765-767. 